This is an electronic reprint of the original article. This reprint may differ from the original in pagination and typographic detail.

Author(s): Hirvonen, Helena

Title: $\quad$ From Embodied to Disembodied Professionalism? Discussing the Implications of Medico-Managerial Management in Welfare Service Work

Year: $\quad 2014$

Version:

Please cite the original version:

Hirvonen, H. (2014). From Embodied to Disembodied Professionalism? Discussing the Implications of Medico-Managerial Management in Welfare Service Work. Social Policy \& Administration, 48(5), 576-593. https://doi.org/10.1111/spol.12045

All material supplied via JYX is protected by copyright and other intellectual property rights, and duplication or sale of all or part of any of the repository collections is not permitted, except that material may be duplicated by you for your research use or educational purposes in electronic or print form. You must obtain permission for any other use. Electronic or print copies may not be offered, whether for sale or otherwise to anyone who is not an authorised user. 
Helena Hirvonen

FINAL DRAFT

\section{From embodied to disembodied professionalism? Discussing the implications of medico-managerial management in welfare service work}

Welfare service work is traditionally understood to comprise embodied, situational and social practices of care that are central to a worker's professional self-image. Over the past few decades, public management reforms have called for reassessment of welfare service workers' professional accountability through practices of medico-managerial service management. These practices promote the production of transparency and accountability in welfare services work through checking-based trust and disembodied professional practices. This article argues that the changes in the nature of trust toward welfare service professionals have implications for care work cultures and workers' professional agency that has traditionally built on the idea of the embodied, situational and social practice of welfare service work. Drawing on an interview study with Finnish welfare service workers $(n=25)$, the article analyses front-line workers' descriptions of medico-managerial management in the social and health care sector. The results point to the significance of embodied practices of care in creation of client trust and for workers' professional self-images. The conclusion is that while disembodied professionalism offers opportunities for workers' self-management and evaluation of accountability and transparency of service processes, it may disregard the importance of embodied practices for the workers' professional self-images and client relations.

Key words: welfare service work, public service reform, trust, (dis)embodied professionalism, practices

\section{Introduction}

This article discusses the implications of recent welfare policy shifts on care work cultures, practices, and professional agency in the context of the Finnish welfare state. In line with many other welfare states, the scarcity of public resources and the rapid aging of the population have forced Finland to resort to new steering mechanisms regarding public service production. To obtain measurable results on human service work and to improve the efficiency and quality of health and social care services, the medico-managerial reform in public social and health care services has also meant increasing the use of ICT. 
Importantly, studies have shown that such public service reforms have implications for the roles of the state, the care professionals, and the service users. They call for new trust building mechanisms between these actors (Nicolini 2007, Evetts 2009, Wilson 2002, Orlikowski 2000).

Previous studies on the effects of public sector reforms estimate that established and autonomous professional groups in welfare service work, such as physicians, have fared rather well in terms of maintaining professional autonomy (Kuhlmann 2006, Kurunmäki 2000), while ethical and practical problems have been detected among less powerful occupational groups such as nurses and care workers (Wilson 2002, Davies 1995, Höpfl 2003, Rasmussen 2004, Tronto 2011, Rask and Dahl 2005, Höpfl 2003). In Finland, nurses, social workers and care workers repeatedly report the highest levels of mental and physical strain of all occupational groups (Ylöstalo et al. 2010), along with increased time pressure, poor organization of work, and ethical conflicts due to the scarcity of material and personnel resources (Järnefelt and Lehto 2002, Virkki et al. 2012, Laine 2006: 31). Despite cutbacks and the consequential retrenchment of the universal coverage of welfare services, the responsibility for the execution of welfare services in the Finnish case remains in the hands of municipalities who rely primarily on the public service sector for organizing service provision (Anttonen and Häikiö 2011, Pollitt and Bouckaert 2011). Consequently, the development and organization of care occupations continues to be strongly interlinked with the welfare state itself. With its relatively extensive public service sector, Finland therefore provides an interesting case for studying welfare state 
transformation from the point of view of the sustainability and innovative potential of the Nordic model.

Welfare service work is traditionally understood to comprise embodied, situational and social practices of care (Tronto 1993, Twigg 2006, Davies 1995, Rummery and Fine 2012) that are central to a worker's self-image as a skilled professional ${ }^{1}$. However, assessing contemporary welfare state reforms in advanced societies, Kuhlmann (2006) suggests that public service work increasingly calls for a form of disembodied professionalism which is founded on information, and reasserted with the use of ICT devices (see also Twigg 2000). The idea is to make the results of welfare service work increasingly transparent, evaluable and comparable. While some studies suggest that welfare service professionalism is 'fluid' and resistant to standardization of its practices (Kirkpatrick 2006, McDonough 2006, Sawyer et al. 2009, Brown and Calnan 2011), this article further highlights the importance of the embodied nature of welfare service work for establishing trust in client/patient relations and in developing positive professional self-images for the front-line workers.

The study of working practices, workplace interactions and activities is of particular importance under conditions of rapid change in working life (Corradi, Gherardi and Verzelloni 2010). This article focuses on the changing nature of professionalism in the female-dominated, lower levels of the welfare service hierarchy, a topic that has received little attention in relation to the effects of the growing digitalisation and use of ICT on the embodied, situational, and social nature of care work. The article is based on an interview 
study with Finnish public service workers $(n=25)$ in fields of nursing, care work, and early education. The aim is to identify the different kinds of embodied and disembodied practices that emerge from the descriptions of the medico-managerial management given by the workers in their interviews. Further, I ask how these practices encourage or delimit workers' chances for meaningful agency, and what kind of professionalism the medicomanagerial management promotes in welfare service work. The article has relevance for discussions on public service management in the context of welfare service work. Also, because welfare service occupations continue to be highly female-dominated the public debate on the effects of welfare state reform also touches on the question of gender and power in the labour market. Methodologically, the article relies on the growing body of practice research (Gherardi 2006, Goldkuhl 2011), as it takes local practices of care and care management as a vehicle for studying public service reforms from the point of view of the professional agency of public service workers.

\section{The reconstruction of public service work}

Evetts (2009, 261), among others, estimates that advanced societies have experienced an overall decrease in the cultural value of professionalism, while trust has become the focus of debates and rhetoric in the context of public service reform (cf. Giddens 1991, Clarke and Newman 1997, Power 1997). At the same time, managerial monitoring of the costs and quality of public services and their outcomes has increased in the social and health care sector (Reinders 2008: 567). In the Finnish welfare state, public service 
transformation has taken place over the past three decades as a gradual process of streamlining the role of the state, strengthening municipal autonomy and restraining public expenditure in the municipalities, who employ about three-quarters of the public sector workforce (Pollitt and Bouckaert 2011: 265). The cautious, incremental implementation of a medico-managerial management has brought with it a strong emphasis on the medical and technical competence of welfare service workers, while the element of social care at the heart of many welfare service occupations, such as practical nursing and early education, has become increasingly regarded as a "non-professional" activity (Laurén \& Wrede 2008, Henriksson \& Wrede 2012, Alasuutari and Markström 2011) $)^{2}$. The situation in Finland resembles a shift from a 'pure' to 'hybrid' professionalism that blends professional and managerial values in health and social care (Noordegraaf 2007, Baines 2004, Carey 2008, Saywer et al. 2009, Baines 2004, Carey 2008, Reinders 2008, Newman and Glendinning 2008), and prioritizes educational content over care in early childhood education work (Naumann 2011, Cohen, et al. 2004, Lewis 2003).

While citizen trust towards the welfare state remains relatively high in Finland, declining popular trust in professionals has strengthened the current belief in the utility of biomedical and managerial knowledge and increased the control of this knowledge over welfare service work in the name of public safety. For example, Total Quality Management and ISO 9000 approaches to service quality improvement have been widely adopted in Finnish local government (Rajavaara 2007, Pollitt and Bouckaert 2011: 264). In line with developments elsewhere (see Hupe and Hill 2007, Brown and Calnan 2011, 
Banks 2004, Luzio 2006), control and power over welfare service work in the Finnish municipalities is increasingly in the hands of managerial elites and politicians, while medico-managerial exigencies are gradually influencing the everyday work of welfare service professionals in hospitals, care homes and kindergartens.

According to Luzio (2006: 560-561), the situation illustrates parallel changes in attitudes towards professionals as well as changes in knowledge production and the organization of professional work. According to her, the crucial question is whether professionalism, when controlled by managers, supervisors, and employers, leads to an increase or a reduction in client trust (see also Brown and Korczynski 2010). Client trust in the context of welfare service work refers to service users' risky investment in an asymmetrical, complementary relationship with welfare service workers (Luzio 2006: 553, see also Dinc and Gastmans 2012). In this context, trust is a mechanism through which the gap between the client's incomplete information and need for help on the one hand, and impossibility of controlling professional work on the other hand is bridged.

\section{Towards efficiently managed and disembodied care professionalism}

Care is the core task of welfare service work, cultivated through corporeal habits and practices that aid the worker's imaginative ability to empathize with others (Twigg 2000). People who are described as caring are often those who can "sense" the needs of another and respond accordingly. Sometimes, such caring habits come easily; at other times, for example in the context of paid work, they may involve sacrifice, pain, and great effort of 
will (Hamington 2004: 31). The empathetic and emotional component of care is crucial in welfare service work, where people often have little knowledge of their clients or patients. It motivates workers to both care for and care about the recipients of care (Tronto 1993, Waerness 1984).

However, researchers suggest that in contemporary societies care has become a more complex issue than this. While the embodied nature of care has traditionally been at the core of care professionalism, they fear that medico-managerial rationality renders the body invisible, overlooking the embodied and gendered nature of care, as well as the bodywork and dirty work that caring entails (Lawler 1997, Twigg 2006: 150, Davies 1995). In line with these fears, current requirements concerning workers’ competence and accountability highlight appropriate medical, technical, and ethical conduct in relation to service users, and workers' personal responsibility for efficient use of public resources. According to Calnan and Rowe (2008), professional trust can no longer be assumed as embodied in the professional; instead, it has to be earned through careful, explicit documentation of daily work.

Kuhlmann (2006) suggests that mechanisms of checking-based trust transform professionalism so that it is no longer embodied in the professional, but becomes disembodied, founded on information and produced through the professional. As workers spend more time on reporting and managing their activities in an effort to make welfare service work quantifiable and transparent, they are, paradoxically, increasingly dissociated from the face-to-face care that gives service users the chance to assess 
workers' trustworthiness. Rather than just 'tasks', Wynsberghe (2011: 11) suggests that care tasks are rich practices that promote values, such as human dignity and compassion, which are difficult to standardize ${ }^{3}$. In light of this, the promotion of disembodied professionalism may greatly impact the nature and values of welfare service work and care practices.

While dependability in worker-patient relations has always been central to the ethics of welfare service work, today, this trust is increasingly pursued with disembodied means of bureaucratic regulation, control, and with increasing use of various technologies (Pollitt and Bouckaert 2011). According to Dunleavy et al. (2005), IT and information system changes play a central role in the cultural, organizational, political and behavioural changes that are taking place in public service delivery. The growing emphasis on personalization and individual choice for service users further reworks client and patient relations (Mitchell and Glendinning 2008). Often, the introduction of technological aids, devices, and software applications aims at easing the physical work of care and enhancing information flows between workers, service users and service managers. However, the use of such tools also raises ethical issues and doubts concerning the appropriate, humane treatment of clients, including their right to privacy (Wynsberghe 2011, Nicolini 2007, Garrett 2005, ETENE 2010). Moreover, workers are often excluded from the decision-making concerning the introduction of technology into their workplaces, which complicates the implementation of such technology and may jeopardize its desired outcomes (Wilson 2002, Hedström 2007, Raappana and Melkas 
2009). Overall, previous studies suggest that practices of checking-based trust lead to rather comprehensive alterations to welfare service work.

\section{Method and data: Analysing the habitual and social practice of care}

In this study, qualitative research methods were used to analyse welfare service workers' descriptions of contemporary care practices. Thematic interviews were collected in 20072009 by using snowball sampling and by recruiting interviewees through adverts posted in welfare service facilities. The aim of the study was to gather accounts of organisational life and organisational change in light of interviewees' identity work as welfare service professionals. The 25 interviewees in the data were nurses and care workers from public hospitals and clinics, municipal geriatric care units, kindergartens, and home care service teams (see Appendix 1). The interviewees were 25-61 years old and 23 were women, and hence the sample was representative of the gender distribution in the social and health care sector. The interviews, which lasted approximately one and half hours each, were recorded and manually transcribed. The interview themes focused on the nature of the participants' jobs (duties, most/least liked elements) and their relationship with coworkers and service users (see Appendix 2). Overall, the aim was to map their accounts of organisational life and the changes in it. The question of care management touched upon several interview themes, for instance the interviewees' perceptions of workers' and service users' rights and responsibilities, and their descriptions of the distribution and adequacy of the material, temporal, and personnel resources in their workplaces. 
In this article, care is understood as a situational, social and embodied practice (Bourdieu 1984) that is based on care ethics and on shared, occupational values among welfare service workers. In the occupational sense, care involves personal service, a form of bodywork, and emotional commitment to the needs of another human being ${ }^{4}$ (Tronto 1993: 108, Held 2006: 37, Sevenhuijsen 1998, Waerness 2005). The practices of care represent potential actions that can be done, asserted, performed — that is, practised—in social contexts by individuals (cf. Martin 2003: 351). From a methodological point of view, a practice-based approach means analysing the interviewees' seeing, saying and doing that concerns their everyday work and follows their shared cultural values that in turn are embedded in society's institutions ${ }^{5}$ (Gherardi 2006, Nicolini 2007, Kuhlmann 2006: 608, Goldkuhl 2011). In the analytical process, I first focused on identifying embodied/disembodied care practices in the data, and then further analysed the interviewees' descriptions in light of their professional agency. The results are presented in the following sections.

\section{Contemporary practices of medico-managerial care}

The interviewees, who represented various occupational groups of welfare service work, all recognized the contemporary call for managerial control and transparency in their work. A care worker from a kindergarten described the consequences of medicomanagerial management in the following manner: 
I mean, like, everything needs to be reported in writing, and it takes an awful lot of time away from the children. And I've noticed that it has increased. And my older colleagues, they're completely lost, asking whether we really need to do all this. We laugh at it sometimes, like, if I blow someone’s nose, should I report that somewhere, too?! (12)

Her frustration with the extent to which kindergarten workers are expected to report even the most menial tasks of childcare work illustrates the efforts to produce transparency in care services. The deployment of technology enables standardized, comparable information to be gathered from different types of care facilities. Typically, ICT systems are brought in for this purpose, forcing front-line workers to the regular adoption of new software applications.

Besides carrying out the practices of check-based control, welfare service workers are involved in provision of the hands-on care and help to their clients and patients. The interviewees' descriptions show the importance of this task in contrast with the effort and resources that they are expected to put into quantifying, reporting and documenting their tasks and the outputs of client and patient care. In this respect, a nurse questioned the purpose of the reporting practices in her unit:

The reporting has changed from paper to electronic forms. And the daily reports we need to fill in keep changing, too. Not all units do this, but we are required to 
report how many children we've kept in respirators, if we’ve used extra personnel from outside our unit, and so on. And they say that the reports affect the decisions regarding our resources. But it’s still sometimes frustrating to fill them out. Like, does anybody really read them? Maybe the unit manager does, but she is somehow so high and mighty that she doesn't even bother to come and see how we're actually doing. So how is she supposed to make sense of the reports we fill out for her? (13)

According to Clarke and Newman (1997: 66), careful reporting produces the kind of transparency that is important for legitimating managerial practices (see also Ferlie et al. 1996, Dahl 2009). As individual workers in public service facilities are increasingly held accountable for the efficient use of public resources, the threat of resource cuts is a powerful argument with which to justify reporting, as the nurse in the previous quote points out. Further, her description points to the difficulty of revealing the subtleties in 'how we're actually doing' through the use of standardized reports. Her criticism suggests that as a way of developing workers' self-assessment and self-management, medico-managerial practices leave room for improvement in terms of the quality of the information that is produced.

The emergence of standardized reporting practices is only one of the implications that medico-managerial management has for care work cultures, practices and professional agency. Another development is the change in the citizen's role from service user to client, which obliges public service organizations to tailor and market their services to 
citizens (Le Grand 2003, Kirkpatrick et al. 2005, Noordegraaf 2007). Service

marketization entails an expectation that workers are able and willing to engage in selfregulated professional development, as well as to commit to the goals and ideals of their workplace over and above those of their profession. The interviewees' descriptions show that coming to terms with these expectations challenges their professional identities, as in this extract from an interview with a kindergarten teacher:

Just today, I was talking about this at work - about how we have all these new work groups and areas of responsibility, such as the one for developing workplace safety. And I feel pressured into taking more responsibility and being more involved in all of these, although I'd rather just do the actual work. (...) I feel like this is not what I wanted. I wanted to do the job as I am, with my own personality. And now it just feels like it's not enough, like they're expecting something else of me. (15)

The contradiction between her self-image and the organization's expectations result in identity loss and a feeling of inadequacy. The medico-managerial vision promotes efficient organizational management through discourses of enterprise, quality, and customer care that assign a worker's role in the workplace according to his or her employer's competitive service strategy. This generates market-oriented and standardized professional practices, and promotes scientific objectivity and technical know-how as the core elements of welfare service work. In so doing, it essentially departs from the traditional discourse of public service professionalism that assigns a worker's role in the 
workplace as defined by his or her professional association and encourages care-oriented, embodied, and situational professional practices (cf. Evetts 2009: 255, Wilson 2002, Davies 1995). The kindergarten teacher, disconcerted, went on to describe how she had learnt during an in-service training course that "each new child in the kindergarten represents the sound of money dropping into the cash register”. Her concern about this image echoes what Henriksson and Wrede (2008: 26) have described as an ideological shift in the Nordic welfare states from a rationality of care to rationality of efficiency (see also Twigg 2000). Furthermore, her concern points to the workers' difficulties of coming to terms with the ideological shift and expectation of a market-oriented outlook on care.

The interviewees' descriptions of medico-managerial management show that workers place a high value on the embodied, situational, and social nature of care practices, which is important for the construction of their professional self-image. While administrative tasks are inherent in welfare service work, many interviewees expressed concern that the contemporary drive for reporting what was understood as "the results" of welfare service work was increasingly pulling them away from the person-to-person care of patients and clients. For the workers, in contrast, the results, as one of the kindergarten teachers explained, were produced in the situational and social dealings with the service users:

A good day is the kind of a day during which I remember I've actually met the children. It's the most important thing. Like, last Monday a young boy said to me after his afternoon nap “Hey, Marja, you're here!” And then he looked at me and said "You're often here but, like, not really here”. And that's when I felt really 
bad because I have all these meetings and such, which is why I'm often only sort of present for the children at work. (7)

Her description is representative of other interviewees' experiences of having to be increasingly engaged in practices of monitoring, planning and reporting the outcomes of their tasks. These practices, as the subsequent analysis will show, presume and promote a disembodied form of professionalism that rests on the understanding of professional trust as being founded on information and produced through the worker (Kuhlmann 2006), instead of being produced in the interrelationships with the service users.

\section{From embodied to disembodied professional practice}

Medico-managerial management has introduced the requirements of self-assessment, organizational commitment and customer care into welfare service work. These requirements challenge and shape the nature of care practices and the front-line workers' professional self-image and agency, producing both positive and negative outcomes. Regarding the positive, a child care worker, for one, explained how the new practice of drafting individual educational plans for each child provided her with a way to assess her own professional skills and development:

The thing with the individual educational plans is that if I succeed in making the goals realistic for each child, the plans allow me to see the progress we've made later on, which is really rewarding. It's rewarding to see that I've succeeded, even 
if it's only about small steps in each child's development. So, there's a challenge in drafting each plan. (12)

The care worker recognizes the potential of the written plans in terms of developing the quality of care as well as her own skills. To her, the plans are a sensible means of professional self-management that serve the good of the organization, the service users, and the worker.

Similarly, a nurse from a home care service team explained how technological development and the concurrent implementation of new managerial practices worked to the benefit of her interrelationships with service users in the form of an electronic patient register:

If I don't have the time to use Effica (electronic patient register) to read the patient files, it seems crazy to go into the clients' homes because then I can only do the necessary basic tasks. I don't always have the time, but when I do, I try to read their files the day before, to check who I'm supposed to see the next day, to go through their medical history, their life history, and to get an overall picture. It feels meaningful to be able to piece together their life situations. It allows me to help them the best way I can, so that it's not just separate tasks I do here and there.

Electronic registers are a valuable source of information, and in the best case, they enhance communication and help to build trust in care relationships. However, having 
access and - more importantly - the time to use electronic registers, is crucial for the successful implementation of technological devices in welfare service work.

Registers and explicit self-assessment practices represent key features in enhancing the transparency of welfare service work. Previous studies suggest that professionals can harness their potential into a new kind of "know-how" with which to establish trust in care relationships and justify the importance of their work (Leppo and Perälä 2009, Van Loon and Zuiderent-Jerak 2011). However, the data show that disembodied practices of medico-managerial care can also result in mistrust toward service personnel. The choice and voice given to service users as attentive consumers may create tension in the relationship between worker and service user, as a geriatric care worker recalls:

With some people it's like "because we pay for this, we should get this and that", and no matter how much you try to explain that you don't always have the time, you are still expected to do more. And if you forget to write down or tick a box in some chart that states that you've given them the eye drops, it's like the end of the world to them - even when you actually carried out the procedure and only forgot to write it down. So, we joke about it, like "Always remember to tick the box, even if you don’t give them the eye drops!” (17)

Her account reveals the difficulty of reducing the workers' accountability and trust in client and patient relationships into disembodied, standardized reporting practices. The work of the front-line welfare service personnel largely remains hands-on, situated and 
embodied, and relies on the workers' practical skills and sense in creating trustful relationships with service users and in responding to their needs. To this end, medicomanagerial practices of disembodied care alone may be insufficient as they distance the worker from the embodied practice of care.

One of the interviewees, a head nurse who was responsible for the majority of the administrative tasks in a geriatric care home, explained how she solved the dilemma of reasserting dependability in the face of disembodied management practices by simply keeping her office door open. This enabled her to attend to her administrative work while keeping an eye and an ear on the everyday activities in the care home:

The residents often like to come in to say hi and sit down in my office. They don't necessarily pay much attention to what I'm doing, so, I think it's OK because they are safe and under my eye there. It's better than if they'd tag along with one of the care workers who was busy doing her chores. Plus, the residents have their security bracelets, so they can’t leave the ward without us noticing. So, if they're just looking for some company, they might as well come into my office. (Q: And it doesn’t bother you?) No, on the contrary! It’s very welcome. I keep the conversation light, and they often repeat the same stories anyhow, since they all suffer from memory disorder. So no, having them come into my office doesn't really disturb my concentration on the paperwork. (11) 
The quote demonstrates how situational and social practices can help in accounting for the quality and output of welfare service work. Keeping her office door open allows the head nurse not only to observe "how the people are actually doing" in her unit, but to participate in their care. However, it should be pointed out that head nurses have more professional autonomy and leverage to control their work than most workers in social and health care facilities. The interviewee in question may therefore be better equipped to manipulate the medico-managerial management of care with situational, social and embodied practices than other workers.

\section{Acknowledging the plurality in ways of knowing}

Analysis of the interviewees' descriptions suggests that situated, social and embodied care practices are elementary for the front-line welfare service workers in terms of the production of positive professional self-identities. A practical nurse from a geriatric care home illustrated this by recalling the mundane act of serving afternoon coffee to one of her clients:

If I'm able to do my job with the clients so that they're satisfied, it pleases both them and me. Last summer, I got so sick of this job. But then, one day, I was helping this lovely old lady with her afternoon coffee. She was so old and tired, like any day could be her last. So, I helped her, and she had her eyes shut as she was sipping the coffee, when she began smiling and said "This is perfect, thank you”. And that's when I felt like I remembered again why I do this job. It's in the small things such as this. (16) 
Her recent struggle to find a sense of purpose in her work demonstrates the importance of situational, embodied and social care practices to welfare service workers' self-identities. However, many interviewees explained that they did not have enough time for the kind of care practices that build worker-patient trust based on touch, communication, eye-contact and sensing of the other's individual needs. According to Andersson (Andersson 2008), the essence of providing 'good' care is in taking the time to show that one cares about the person in need of care. Small gestures convey a sense of responsibility on the part of the worker, which can even extend beyond their set working hours.

Many of the interviewees recalled past experiences, memories and future expectations while pondering the life situations and future of the cared-for, and expressed concern over them. Mariella Pandolfi (Pandolfi 1990, Pandolfi 1990) has stated that people carry in their bodies more than just their personal experiences of joy and suffering. Hence, our bodies are the containers, bearers, reminders and crossroads of other people's actions and memories. One of the nurses described her experience in a terminal care unit, pointing to how a worker can feel the pain of the cared-for in her own body, which extends her feeling of responsibility beyond the workplace and working hours:

I'd say it's the patients who are restless or those who are in a lot of pain. They kind of take you over, to the extent that you can physically feel their pain yourself. Those are the ones that can also stay to haunt you in your free time. (21) 
Her description demonstrates how professional responsibility intertwines with embodiedness, and how care work rests on a plurality of ways of knowing, including the ontological and felt, as Lawler (1997: 33) has pointed out. In the same vein, Calnan and Rowe (2008) state that the sources of professional trust in contemporary health care services continue to lie in the quality of the patient-worker interaction, and in the competence and empathy that is displayed through this, rather than in informed trust based on the production of abstract and disembodied data. The broad range of care practices that the analysis revealed can help us understand the agentic choices open to workers, along with their disposition and attitudes, in which embodied practices are a crucial part and remain central to their professional self-images.

\section{Conclusions}

In this article I analysed Finnish welfare service workers’ descriptions of the effects of medico-managerial management reform in the context of nursing, care work, and early education work. More specifically, I looked at its effects on care practices and the professional self-image and agency of the front-line workers. Overall, the results point to a qualitative turn from embodied to disembodied professional practices in welfare service work and to the promotion of certain values over others. Workers' accountability is asserted in a complex network where, on the one hand, disembodied practices create opportunities for professional self-management. On the other hand, medico-managerial management leaves less room for the kinds of embodied, situational and social practices of care that are at the heart of welfare service workers' professional self-image as “embodied practitioners”, as Twigg (2000: 89) describes them. 
In aging societies, service users increasingly require help and assistance that - to a great extent - requires embodied care. Yet, as Twigg (2006: 173) points out, the work of social and health care professionals is not being articulated any more body consciously than before because the world of policy making - where problems are presented in abstract, neutral terms - is a disembodied one. On the contrary, as this article suggests, care professionalism is regarded and managed in increasingly disembodied terms. Further, the results suggest that as a way of maintaining and restoring accountability in professionals, disembodied medico-managerial practices alone are insufficient for establishing trust between service-users and workers. As a mechanism for legitimating professional work, they may increase transparency and accountability, but can also lead to the marginalisation of more practical and caring approaches to human service work. Audits based on medico-managerial practices may therefore rather inhibit than open up new discussion and opportunities for increasing service quality, as envisioned by Clegg (2008).

Changes in practices, as Nicolini (2007: 916) suggests, involve both empowerment and disempowerment. In the Nordic welfare states, public service policy making affects not only the institutional environment of service production, but also the existing idea of care professionalism. The risk in medico-managerialist management, and the rather narrow account of care practices they produce, is that it hampers recognition of the embodied occupational skills, goals, and knowledge of care workers, who enjoy limited chances of professional self-management but have a great responsibility for producing measurable quality outputs of care. Moreover, in the female-dominated lower levels of the 
occupational hierarchy of welfare services, medico-managerialism may further confirm existing hierarchies and segmentation between medical and holistic care, between feminine and masculine, and embodied and disembodied care.

Kuhlmann (2006) proposes that the indirect and impersonal nature of disembodied professionalism could help challenge the idea of women as natural carers. Yet, in fields such as welfare service work disembodied practices form only one component in the range of workers' skills. Moreover, Western welfare states implicitly continue to rely on a gendered division in the labour market and society as a whole. According to this division, women in general, and welfare service workers in particular, are called upon to respond to the growing care needs of aging populations as "natural carers" and flexible workers (Acker 2006, Davies 1995, Henriksson 2008). Despite the possibilities Kuhlmann (2006) outlines for disembodied professionalism, the results in this article point to considerable challenges to the effective realization of these possibilities due to welfare service workers' limited autonomy and the disregard shown for the embodied practice of care under medico-managerial management in the public service sector. Nevertheless, the results also point to the workers' ability to negotiate and execute disembodied practices of care in a manner that is supportive of their self-images as skilled workers. The conclusion is that appreciating and supporting embodied practices of care work could benefit the empowerment of lower level occupational groups, restore and build trust in relation between professional and client, and enhance the diversity of professional knowledge in social and health care work. 


\section{References}

Acker, J. (2006), Class questions: Feminist answers. Lanham, Md: Rowman \& Littlefield).

Alasuutari, M. \& Markström, A-M. (2011), The Making of the Ordinary Child in Preschool, Scandinavian Journal of Educational Research, 55, 5: 517-535.

Andersson, K. (2008), The Neglect of Time as an Aspect of Organising Care Work. In S. Wrede, L. Henriksson, H. Host, S. Johansson \& B. Dybbroe (eds), Care work in crisis: reclaiming the Nordic ethos of care, 1. ed. edn, Lund: Studentlitteratur, pp. 341-361.Andersson, K. 2008. The Neglect of Time as an Aspect of Organising Care Work. In S. Wrede, L. Henriksson, H. Host, S. Johansson \& B. Dybbroe (Eds.) Care work in crisis : reclaiming the Nordic ethos of care. (1. ed. edition) Lund:

Studentlitteratur, 341-361.

Pandolfi, M. 1990. Boundaries inside the body: Women's sufferings in Southern Peasant Italy. Culture, medicine and psychiatry 14 (2), 255-273.

Appendix 1: table of interviewees

\begin{tabular}{|l|l|l|l|}
\hline & Occupation & Workplace & Age \& gender \\
\hline 1 & Psychiatric nurse & Psychiatric outpatient clinic & 52, woman \\
\hline 2 & Social worker & Psychiatric open ward & 61, woman \\
\hline 3 & $\begin{array}{l}\text { Paramedicl } \\
\text { Emergency medical } \\
\text { technician }\end{array}$ & Emergency ambulance service & 27, man \\
\hline 4 & Mental health nurse & Psychiatric open ward & 51, woman \\
\hline 5 & Registered nurse & Acute rehabilitation unit & 37, man \\
\hline 6 & Care worker & Social care agency & 52, woman \\
\hline 7 & $\begin{array}{l}\text { Kindergarten } \\
\text { teacher }\end{array}$ & Day nursery & 44, woman \\
\hline 8 & $\begin{array}{l}\text { Kindergarten } \\
\text { teacher }\end{array}$ & Day nursery & 45, woman \\
\hline 9 & Registered nurse & Geriatric nursing home & 53, woman \\
\hline 10 & Public health nurse & Geriatric home care unit & 58, woman \\
\hline 11 & Head nurse & Geriatric nursing home & 38, woman \\
\hline 12 & Care worker, BA & Day nursery & 27, woman \\
\hline 13 & Registered nurse & Paediatric intensive care unit & 45, woman \\
\hline 14 & Registered nurse & Acute rehabilitation unit & 29, woman \\
\hline 15 & Care worker, BA & Day nursery & 33, woman \\
\hline
\end{tabular}




\begin{tabular}{|l|l|l|l|}
\hline 16 & Registered Nurse & $\begin{array}{l}\text { Geriatric nursing home / chronic } \\
\text { care }\end{array}$ & 30, woman \\
\hline 17 & Care worker, BA & Geriatric home care unit & 36, woman \\
\hline 18 & $\begin{array}{l}\text { Assistant head } \\
\text { nurse }\end{array}$ & Acute rehabilitation unit & 53, woman \\
\hline 19 & Registered nurse & Home care agency & 45, woman \\
\hline 20 & Care worker & Home care agency & 50, woman \\
\hline 21 & Registered nurse & Geriatric care unit & 27, woman \\
\hline 22 & $\begin{array}{l}\text { Registered \& public } \\
\text { health nurse }\end{array}$ & Home care unit & 25, woman \\
\hline 23 & $\begin{array}{l}\text { Kindergarten } \\
\text { teacher }\end{array}$ & Day nursery & 45, woman \\
\hline 24 & $\begin{array}{l}\text { Kindergarten } \\
\text { teacher }\end{array}$ & Day nursery & 35, woman \\
\hline 25 & Registered nurse & Home care unit & 43, woman \\
\hline
\end{tabular}

\section{Appendix 2: List of questions}

1. Tell us about your background: education, age, work history in the field.

2. Tell us about your previous day at work. What were the memorable moments, the pros and cons? Why these?

3. Was it a particularly tough day? How would you describe a tough day?

4. As a nurse/social worker, what is most essential in your work and what are the skills you would personally like to develop as a nurse/social worker?

5. Have you experienced any changes in your work environment in the organization or in the atmosphere in the past decade? If so, how would you describe these changes?

6. Do you think there is a need for workers to have a capacity to constantly change their procedures at work? Tell us about the challenges you've experienced regarding this.

7. Do you recognize an emphasis on customer orientation in your work? Do you address the service users as customers, clients or patients?

8. How would you describe the everyday encounters between you and the service users? For you, what is the key to a successful relationship with them? What retains and what helps this interaction?

9. Feelings and care work: what has recently brought you pleasure, happiness in your work? How about frustration, anger, other negative feelings? How have you expressed these feelings?

10. Tell us about the conflicts between people in you work. How are these situations dealt with?

11. Have you witnessed or experienced violence (verbal, physical) at work? Tell us about these situations. How does it make you feel when targeted at you? At others?

12. What do you think would be the right attitude towards violence in your work? Do you think violence could be prevented by learnt techniques? How have you learnt to cope with threats of violence? 
13. In a few sentences, how would you compare your job as a $(X)$ with other jobs? How is your job different?

14. In general, do you think people understand the quality and characteristics (ethical, emotional) that your work as a $(X)$ includes?

15. How do you feel about the responsibility for the patients/clients?

16. What do you think about the claim that one has to be both sensitive and strong to do care work?

17. Can you give us examples of what strength and sensitivity have meant to you?

18. Can you remember situations where caring for others at work has contradicted your own personal needs? How did it make you feel?

19. Does the care worker's gender make any difference at work? Can you tell us about situations where you've experienced your gender as a strength/weakness at work?

20. If you had three wishes, what would you change and what would you stick with at work?

21. If you had the choice, what would you rather do in your life right now?

22. Can you think of any questions or important areas that should have been included in this interview? Is there anything you'd like to add or clarify?

\footnotetext{
${ }^{1}$ I follow Laiho \& Ruoholinna's (2012) definition of professional identities in welfare service work that comprises the person's self-conception as a professional agent based on his or her life history, how they see themselves, what they want to become, what they relate to and identify with, what they value and what their professional commitments are, including the values and ethics of the work. The venue of constructing professional identities is the socio-cultural context of the workplace.

${ }^{2}$ Historically, the welfare state has had a central role in shaping social and health care occupations and their professionalization in Finland. In line with other Nordic countries, it established a comprehensive public services sector after WWII in parallel with a female, semi-professionalized workforce in social, health care and early childhood education services. The period of rapid public service expansion from the 1960s to the 1980s bound the development and regulation of caring occupations firmly together with the welfare state and its ideology of gendered and classed equality (Wrede 2008: 28).

${ }^{3}$ On the normative nature of care practices, see also Held (2006, 37).

${ }^{4}$ The caring rationality that emerges in the practice of care is a "system of action" that is institutionalized and widely recognized but also dynamic, emergent, local, variable, and shifting.

${ }^{5}$ The practical knowledge in which individuals invest in their ordinary activities is often tacit, and understood by the French sociologist Pierre Bourdieu as their symbolic capital (Bourdieu 1984).

Differences in practices are therefore also symbolic differences that constitute a set of distinctive signs for the individual's position in a societal field such as welfare service work.
} 